\title{
PHEROMONE TRAP COLOUR DETERMINES CATCH OF NON-TARGET INSECTS
}

\author{
G. CLARE $^{1}$, D.M. SUCKLING ${ }^{2,6}$, S.J. BRADLEY ${ }^{3}$, \\ J.T.S WALKER ${ }^{3}$, P.W. SHAW ${ }^{4}$, J.M. DALY ${ }^{2}$, G.F. McLAREN ${ }^{5}$ \\ and C.H. WEARING ${ }^{5}$
}

\author{
${ }^{1}$ HortResearch, Mt Albert Research Centre, PB 92169, Auckland \\ ${ }^{2}$ HortResearch, Canterbury Research Centre, P.O. Box 51, Lincoln \\ ${ }^{3}$ HortResearch, Hawke's Bay Research Centre, Private Bag, Havelock North \\ ${ }^{4}$ HortResearch, Nelson Research Centre, Private Bag, Riwaka \\ ${ }^{5}$ HortResearch, Clyde Research Centre, RD 1, Alexandra \\ ${ }^{6}$ Author for correspondence
}

\begin{abstract}
Pheromone traps were operated in five regions to determine the impact of trap colour on catch of target and non-target insects. Red or green coloured pheromone sticky traps caught fewer native and introduced bees compared to the standard white traps, and yellow or blue traps. Honey bees (Apis mellifera) were caught mainly in white followed by blue traps, while bumble bees (Bombus spp.) were most attracted to blue traps, with most of the remainder caught in white traps. Native bee (Lasioglossum and Hylaeus spp.) catches were greatest in white traps, followed by yellow traps, with a few in green traps. There was no significant difference in catch of the target species, Cydia pomonella or Epiphyas postvittana, with trap colour. Replacement of the white traps with green or red traps is recommended to reduce nontarget impacts on bees.
\end{abstract}

Keywords: pheromone trapping, non-target, bees, codling moth, lightbrown apple moth.

\section{INTRODUCTION}

The New Zealand apple industry is reliant on export markets, which place phytosanitary restrictions on insects and their damage (Batchelor et al. 1997). Leafrollers and codling moth are key pests of apples and are the target of most insecticides in the crop. Concerns about the potentially negative impacts of broadspectrum insecticides on environmental quality, food safety and natural enemies led to research aimed at minimising the use of insecticides for pest management. Pheromone traps have proved to be very useful in the drive to reduce insecticide use in New Zealand apple orchards (Wearing and Charles 1978; Suckling et al. 1988; Shaw et al. 1993). Recording of catches of lightbrown apple moths and codling moths in pheromone traps is now required as the basis for decisions to apply selective insecticides under integrated fruit production of apples (Bradley et al. 1998). Catches of lightbrown apple moths are also being used for decision support in summerfruit integrated fruit production (G.F. McLaren, unpubl. data).

Catch of non-target insects, is sometimes a problem with these traps, but one which has not previously been quantified. Trap efficiency for the target species is also likely to be affected by the presence of other insects on sticky bases. The presence of non-target species therefore represents a nuisance, which may require more frequent sticky base changes. Mortality of trapped honey bees is also undesirable, although the number of bees removed seems unlikely to have significant impacts on pollination. Trap colour, measurable as spectral reflectance, is known to affect the attraction of diurnally-active insects (Childers and Brecht 1996). This study aimed to compare the 
catch of honey bees (Apis mellifera), bumble bees (Bombus spp., mainly B. terrestris) and native bees (Lasioglossum and Hylaeus spp., Halictidae) in the standard white traps, compared to alternative colours. Catch of two target moth species, lightbrown apple moth (LBAM, E. postvittana) and codling moth (CM, C. pomonella), was also evaluated.

\section{MATERIALS AND METHODS}

Pheromone sticky traps (Suckling and Shaw 1990) made of Corflute ${ }^{\mathrm{TM}}$ plastic were used in this study. Traps of five colours were used (white (standard), blue, green, yellow and red). Three replicates of each colour were tested in orchards in three or four regions for the target (LBAM and CM) and non-target species (honey bees, bumble bees and native bees) (Table 1). All tests were conducted in apple orchards, apart from LBAM trapping in Central Otago (apricots). Trapping was carried out between December 1999 and January 2000. Multiple regional locations (Canterbury, Nelson, Hawke's Bay and Central Otago) were used to ensure sufficient insect catches of target and non-target species. A minimum of forty insects per region was the criterion chosen for inclusion in the statistical analysis (ANOVA of log-transformed counts).

The spectral reflectances of each of the plastic trap colours (Childers and Brecht 1996) were measured using an external integrating sphere connected via a fibre optic cable to a Li-Cor 1800 spectroradiometer (Lincoln, NE) and compared to that of a barium sulphate standard. The experimental set-up provided a spectral range of 350$1100 \mathrm{~nm}$, scanning at intervals of $2 \mathrm{~nm}$.

\section{RESULTS AND DISCUSSION}

Catches of the two target moth species were sufficient (Table 1) to determine the influence of trap colour on catch in three (CM) or four regions (LBAM). Trap colour had no significant effect on catch of LBAM $(\mathrm{P}>0.05)$ or $\mathrm{CM}(\mathrm{P}>0.05)$. This result is not surprising for nocturnal insects with their primary behavioural response initiated by the presence of sex pheromone. It confirms that the decision thresholds for application of selective insecticides against LBAM and CM (Bradley et al. 1998) would not be affected by a change in trap colour. Regional differences were detected in moth and bee catches (Table 1) which may be attributable to trap sites. The experiment was not designed to examine regional factors, since trapping was not conducted over a whole season or over exactly the same time periods in each region.

TABLE 1: Total catch of target and non-target species in pheromone sticky traps, in four regions. Native bee catches were not recorded in Hawke's Bay or in Central Otago.

\begin{tabular}{lccccc}
\hline & \multicolumn{2}{c}{ Target species } & \multicolumn{3}{c}{ Non-target species } \\
& E. postvittana & C. pomonella & Bombus spp. & A. mellifera & Native bees \\
\hline Canterbury & 926 & 92 & 205 & 197 & 280 \\
Hawke's Bay & 266 & 166 & 40 & 37 & - \\
Nelson & 114 & - & 57 & 79 & 96 \\
Central Otago & 576 & 363 & 38 & 18 & - \\
TOTAL & 1882 & 621 & 316 & 323 & 377 \\
\hline
\end{tabular}

There were significant differences in the catches of bees with trap colour (Fig. 1). Honey bee $(P<0.001)$ and bumblebee $(P<0.001)$ catches were greatest in white and blue traps. Native bee catches were greatest in white and yellow traps $(P<0.001)$. Both sexes of native bees were caught. Samples from Nelson and Canterbury regions were identified as predominantly Lasioglossum sordidum, with a very few $(<1 \%)$ Hylaeus capitosus and $H$. relegatus. 


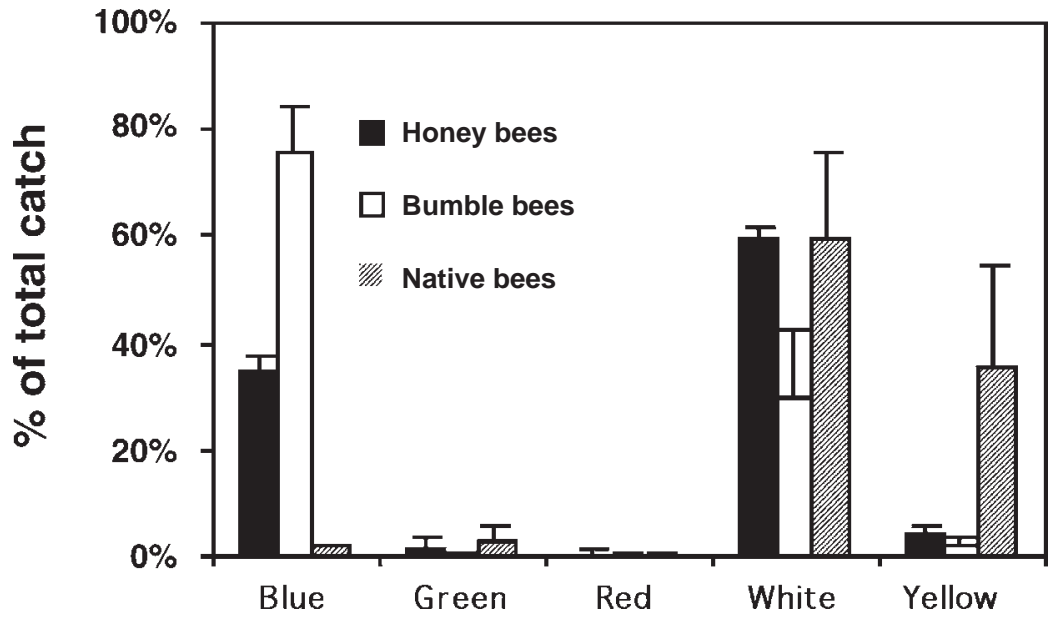

FIGURE 1: Percentage of catch of each bee group in moth traps of different colours. Standard error bars relate to regional variation rather than local replicates. Total catches of each species are in Table 1.

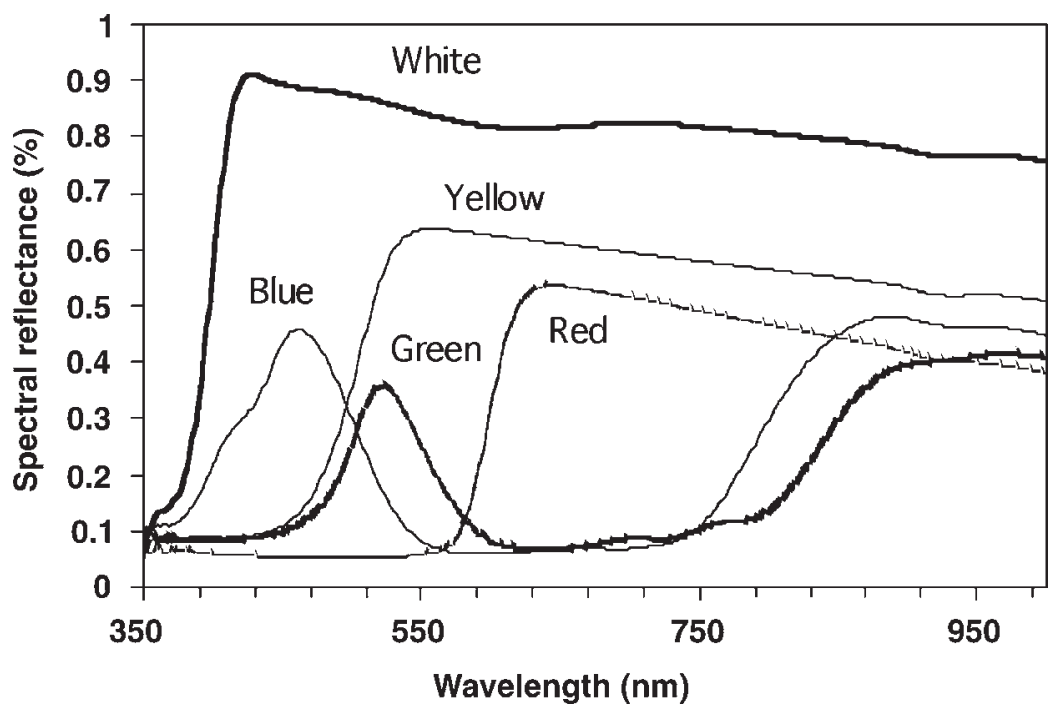

FIGURE 2: Spectral reflectance of white and coloured sticky traps.

White traps reflected a very broad range of light wavelengths compared to the coloured traps (Fig. 2), which explains the high attraction of this trap colour to all three types of bees, despite the differences shown between the types of bees to other trap colours (Fig. 1).

Insect vision has been well studied (Wigglesworth 1972). The trichromatic theory of insect colour vision suggests that insects see three primary colours, yellow, blue and ultraviolet, with the response to any one of these also elicited by mixtures of these colours. The spectral sensitivity of honey bees to wavelengths at or near the ultraviolet 
spectrum is well documented (Ribi 1987; Hertel and Maronde 1987). Honey bees respond to four regions within the colour spectrum: $650-500 \mathrm{~nm}$ (red, yellow and green), $500-480 \mathrm{~nm}$ (blue green), 480-400 nm (blue and violet) and 400-310 nm (ultraviolet). While honey bees do respond to these colours in flowers, their response is often to the reflected ultra-violet components within flower colours. Honey bees are also attracted to at least four colour tones within the blue to ultraviolet wavelengths (Wigglesworth 1972; Chapman 1982). High catches in white traps suggest that honey bees respond to the full spectral reflectance which probably included ultra-violet components not shown in Fig. 2 (i.e. beyond the reliable range of the measuring equipment). Blue traps were only marginally less attractive to honey bees than white traps, which could be expected given their response to blue and ultraviolet wavelengths. Bumble bees were also highly attracted to blue, and it has been noted that many of their preferred flowers are blue (Heinrich 1977).

The preference of the native eusocial bees for yellow (after white traps) was different from results found for the other Hymenoptera. Yellow traps are also useful for catching various parasitic Hymenoptera (D.M. Suckling, unpubl. data), and such a preference presumably relates to flower colour. A strong response in native bees to yellow colour (a primary colour in insect vision) might well be a reflection of the relatively primitive co-evolutionary relationship between native bees and native flowers in our natural environment which was poor in indigenous coloured flowers. Yellow flowers visited by these bees include Corokia cotoneaster (Webb 1994) and matagouri (Discaria toumatou), as well as native dandelions (B. Donovan, pers. comm.).

This study has identified that red and green traps had very low catches of nontarget Hymenoptera, compared to the standard white or blue and yellow traps. In practice, both red and green traps are relatively visible in orchards, although red traps may have greater visibility. Pheromone trap suppliers and users concerned about catching non-target insects can now consider replacing these traps with red or green traps.

\section{ACKNOWLEDGEMENTS}

We thank Kevin Gould, School of Biological Sciences, University of Auckland for the use of the Li-Cor 1800 spectroradiometer and for his helpful advice. Dr Barry Donovan kindly identified the native bees. Thanks are also due to Bernie Attfield and Jenny Fraser for technical assistance.

\section{REFERENCES}

Batchelor, T.A., Walker, J.T.S., Manktelow, D.W.L., Park, N.M. and Johnson, S.R., 1997. New Zealand integrated fruit production for pipfruit - charting a new course. Proc. 50th N.Z. Plant Prot. Conf.: 14-19.

Bradley, S.J., Walker, J.T.S., Wearing, C.H., Shaw, P.W. and Hodson, A.J., 1998. The use of pheromone traps for leafroller action thresholds in pipfruit. Proc. 51st N.Z. Plant Prot. Conf.: 173-178.

Chapman, R.F., 1982. The Insects: Structure and Function. 3rd Edition. Harvard University Press, Cambridge, Massachusetts. 919 pp.

Childers, C.C. and Brecht, J.K., 1996. Colored sticky traps for monitoring Frankliniella bispinosa (Morgan) (Thysanoptera: Thripidae) during flowering cycles in citrus. J. Econ. Entomol. 89: 1240-1249.

Heinrich, B., 1977. Bumblebee Economics. Harvard University Press, Cambridge, Massachusetts. 245 pp.

Hertel, H., and Maronde, U., 1987. Processing of visual information in the honeybee brain. Pp 141-157 In: Neurobiology and behaviour of honeybees, R. Menzel, and A. Mercer (Eds.); Springer Verlag, Berlin.

Ribi, W.A., 1987. The structural basis of information processing in the visual system of the bee. Pp 130-140 In: Neurobiology and behaviour of honeybees, R. Menzel and A. Mercer (Eds.); Springer Verlag, Berlin. 
Shaw, P.W., Cruickshank, V. and Suckling, D.M., 1993. Commercialisation of pheromone trapping in Nelson. Proc. 46th NZ Plant Protection Conf:: 135-140.

Suckling, D.M. and Shaw, P.W., 1990. Preliminary trials of mating disruption of lightbrown apple moth in Nelson. Proc. 43rd N.Z. Weed and Pest Control Conf: 311-316.

Suckling, D.M., Walker, J.T.S., Shaw, P.W. and White, V., 1988. Spray less for leafroller control. The Orchardist of New Zealand November: 21-24.

Wearing, C.H. and Charles, J.G., 1978. Integrated control of apple pests in New Zealand. 14. Sex pheromone traps to determine the applications of azinphosmethyl for codling moth control. Proc. 31st N.Z. Weed and Pest Control Conf.: $229-235$.

Webb, C.J., 1994. Pollination, self-incompatibility, and fruit production in Corokia cotoneaster (Escalloniaceae). N. Z. J. Botany 32: 385-392.

Wigglesworth, V.B., 1972. The Principles of Insect Physiology. 7th Edition. Halsted Press. 827 pp. 